\title{
Conservative treatment of acute appendicitis
}

\author{
Haytham H. Al-Najafy \\ Department of Surgery, College of Medicine, University of Mosul, Mosul, Iraq. \\ Correspondence: Haytham H. Al-Najafy.surgdep.mmc@yahoo.com. \\ (Ann Coll Med Mosul 2018; 40 (1): 56-59). \\ Received: $25^{\text {th }}$ Oct. 2013; Accepted: $22^{\text {nd }}$ Jan. 2014.
}

\section{ABSTRACT}

Objective: To define the value of Tamsulosin drug addition to antibiotics (Ceftriaxone and Metronidazole) in conservative treatment of nonperforated acute appendicitis.

Patients and methods: Prospective clinical study performed in Al-Jamhoory Teaching Hospital covering a period from Jan 2010 to Jan 2012. Formal consent from the patients and ethical approval were obtained. One-hundred and two patients including 74 males and 28 females, with age range of 17-45 years were admitted to the surgical unit number 3 complaining of acute appendicitis. Detailed clinical history was taken and clinical examination was carried out. All the patients had general urine examination (G.U.E), ultra sound (U.S) of the right iliac fossa and determination of serum c.reactive protein level. Those who had complicated appendicitis were excluded from the study. The patients were randomly divided into two groups $A$ and $B$.

Group A: Fifty one patients were given $500 \mathrm{mg}$ of Ceftriaxone and $500 \mathrm{mg}$ Metronidazole, both I.V twice daily.

Group B: Fifty one patients were given the antibiotics regime plus Tamsulosin $0.4 \mathrm{mg}$ orally once daily.

The patients who had good signs of response (decrease or disappearance of the abdominal pain, tenderness and rebound tenderness and return of appetite) in the first 24 hours of the treatment continued the treatment for further 5 days, if there was no good response immediate appendicectomy was done. There was follow up of discharged patients for 4 months.

Results: Group A: Forty-one patients out of 51 (80.39\%) had a good signs of response (decrease or disappearance of the abdominal pain, tenderness and rebound tenderness and return of appetite) within the first 24 hours post presentation while 10 patients needed appendicectomy. Group B: Forty-nine patients (out of 51 ) $96.07 \%$ had good signs of response (decrease or disappearance of the abdominal pain, tenderness and rebound tenderness and return of appetite) within the first 24 hours post presentation and only 2 patients needed appendicectomy. Those who were discharged after conservative treatment were followed up for 4 months. Five patients in group $A$ and 3 patients in group $B$ had recurrence of symptoms and signs of acute appendicitis and appendicectomy was performed for them.

Conclusion: Tamsulosin added to antibiotics for treatment of acute appendicitis is safe and resulted in speedy recovery of the patients with reduced recurrence of the condition.

Keywords: Appendicitis, Conservative treatment.

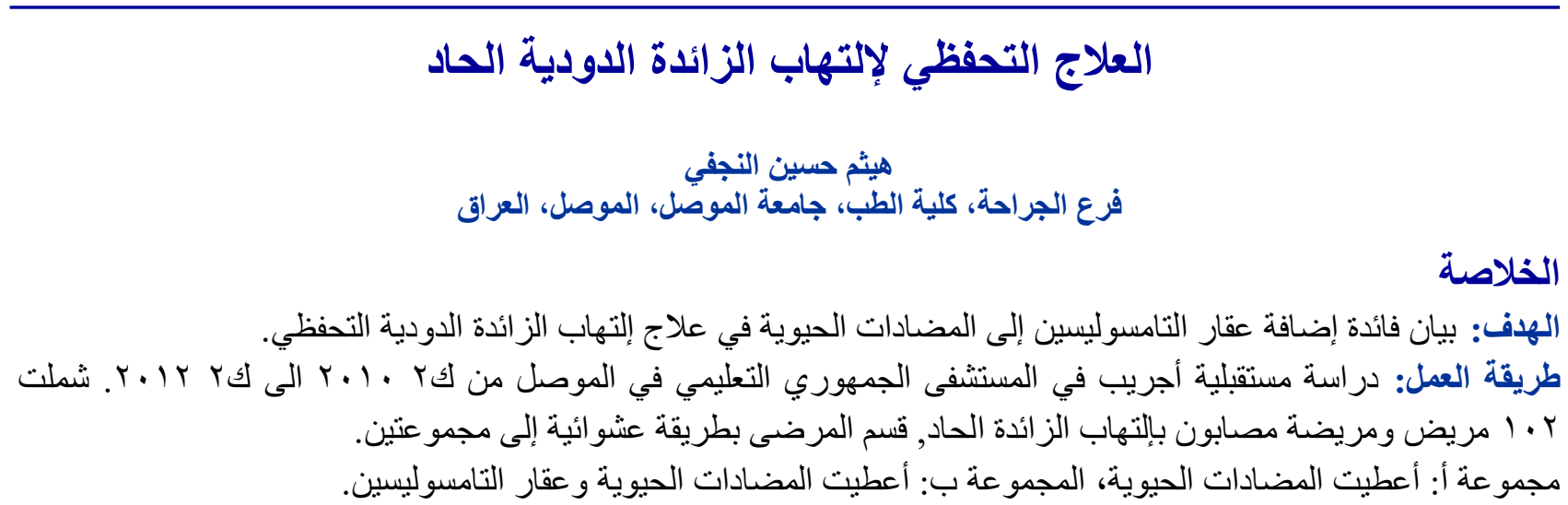




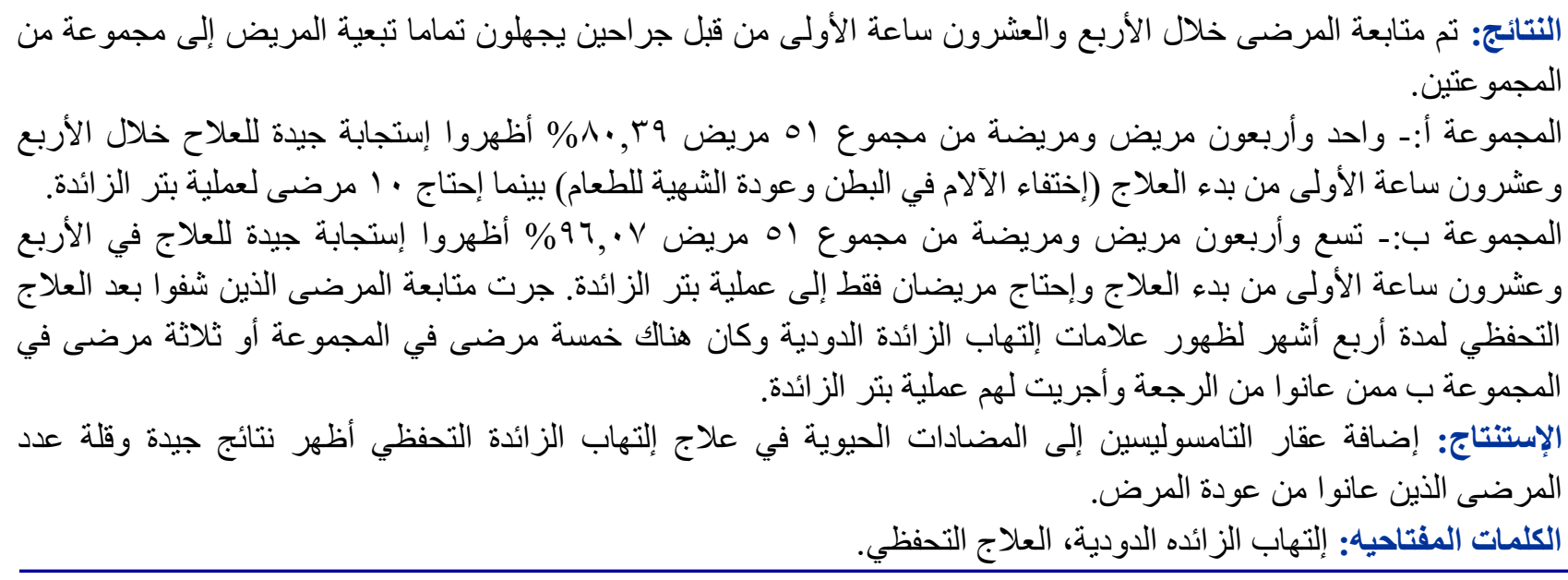

\section{INTRODUCTION}

$\mathrm{n}$ spite of the progress in surgical practice, acute appendicitis is still considered as one of the most common surgical emergencies and appendicectomy is still the most frequent procedure performed. ${ }^{1,2}$ Pathogenesis of acute appendicitis is multifactorial including infection and obstruction. There has been dramatic reduce in acute appendicitis since the use of antibiotics, ${ }^{3,4}$ so it became feasible to treat acute appendicitis conservatively. ${ }^{5}$

In this study, Tamsulosin is used for the first time in combination with antibiotics in conservative treatment of the non-complicated acute appendicitis. Tamsulosin is an alpha $1 \mathrm{~A}$-receptor blocker which relaxes smooth muscles. It is primarily used in the treatment of prostatic hypertrophy. It's main side effect is dizziness. I think that Tamsulosin causes relaxation of the appendicular muscle which enhances the drainage and relieves the intramural pressure of the inflamed appendix. Hence, it gave better results if given with antibiotics in the treatment of nonperforated appendicitis than antibiotics alone.

\section{PATIENTS AND METHODS}

From Jan 2010 to Jan 2012, 102 adult patients complaining from non-complicated acute appendicitis were admitted to the surgical unit number 3 in Al-Jamhoory Teaching Hospital in Mosul. they were 74 males and 28 females. Full history was taken and thorough clinical examination was done. All of the patients were sent for G.U.E, white blood cell (WBC) count, serum c-reactive protein and ultra sound U.S. of the abdomen.
Consent from the patients and ethical approval from the ethical committee were obtained.

The patients were randomly divided into two groups.

Group A:- The patients were treated conservatively with antibiotic only (Ceftriaxone 500mg I.V twice daily with Metronidazole 500mg I.V twice daily).

Group B:- Were given the same antibiotic of group A plus Tamsulosin $0.4 \mathrm{mg}$ orally once daily.

The patients in both groups were monitored blindly by separate surgeons in our unit in the first 24 hours of the treatment for signs of response to the treatment (decrease or disappearance of the abdominal pain, tenderness and rebound tenderness and returning of appetite). Those who showed these signs of response were maintained on the treatment for 5 days. Those who had no signs of recovery in the first 24 hours, appendicectomy were done for them immediately.

Four months follow up for those who were discharged from the hospital was carried out.

\section{RESULTS}

Group A:

Forty one patients out of 51 (80.39\%) showed good response (decrease or disappearance of the abdominal pain, abdominal tenderness and rebound tenderness and returning of appetite) in the first 24 hours of treatment with the antibiotics while ten patients showed no such signs. Appendicectomy was performed for them.

Group B:

Forty-nine patients out of 51 (96.07\%) showed good signs of response and recovery and only 2 patients needed appendicectomy. 
Table 1 shows the number of patients with recovery in the first 24 hours in both groups.

Good response of the patients in both groups in relation to time table in the first 24 hours of the conservative treatment showed clearly that the response to the treatment started earlier in group $B$ than those in group $A$ and the final result is much better in group $B$ than in group $A$ as demonstrated in Table 2.

Good appetite returned after 10-16 hours from the commencement of the conservative treatment in 44 patients in group $B$ while 38 patients in group A did so.

Patients with high c.reactive protein level (4 $\mathrm{mg} / \mathrm{dL}$ ) (10 patients in group $A$ and 2 patients in group B) showed high index of failure of the conservative treatment in the first 24 hours (persistent and increase of the abdominal pain, tenderness, and rebound tenderness). Also the recurrence rate of acute appendicitis after 4 months of follow up is noted to be high in patients with high c.reactive protein level.

Recurrence of signs and symptoms of acute appendicitis after 4 months of follow up occurred in $5(9.8 \%)$ patients from group A, $3(5.9 \%)$ patients in group $B$, and all were operated upon immediately.

Ultra sound (US) examination of the abdomen showed no calcification in the appendix. No mortality was recorded in both groups.

Table 1. Number of patients recovered within the $1^{\text {st }} 24$ hours of treatment.

\begin{tabular}{lccc}
\hline Group & $\begin{array}{c}\text { No of } \\
\text { recovered } \\
\text { patients }\end{array}$ & $\begin{array}{c}\text { No of } \\
\text { patients } \\
\text { needed } \\
\text { operation }\end{array}$ & Percentage \\
\hline Group A & 41 & 10 & $80.39 \%$ \\
\hline Group B & 49 & 2 & $96.07 \%$ \\
\hline
\end{tabular}

Table 2. number of patients recovered in both groups in relation to the time table in the first 24 hour of the treatment.

\begin{tabular}{lcccc}
\hline Groups & $\begin{array}{l}4-10 \\
\text { hours }\end{array}$ & $\begin{array}{c}11-16 \\
\text { hours }\end{array}$ & $\begin{array}{c}17-24 \\
\text { hours }\end{array}$ & $\begin{array}{c}\text { No } \\
\text { response }\end{array}$ \\
\hline Group & 6 & 20 & 15 & 10 \\
A & Patients & Patients & Patients & Patients \\
Group & 12 & 29 & 8 & 2 Patients \\
B & Patients & Patients & Patients & \\
\hline
\end{tabular}

\section{DISCUSSION}

In spite of all the medical progress acute appendicitis is still considered as one of the most surgical emergencies and appendicectomy is still the most frequent surgical procedure performed. ${ }^{1 \text {, }}$ ${ }^{2}$ In the United States nearly 300,000 appendicectomy is annually performed. ${ }^{6}$ Nearly $50 \%$ of all emergency appendicectomies were performed on normal or mildly inflamed appendix. ${ }^{7}$

The advent of antibiotic use caused drastic reduction in both mortality and morbidity of acute appendicitis. $^{8}$ Hence, conservative treatment of non-complicated appendicitis became more popular. ${ }^{9}$ In this study, Tamsulosin is added to the antibiotics regime (Ceftriaxone and Metronidazole). In conservative treatment of non-complicated acute appendicitis the use of this mixture yielded an excellent results in group B (96.07\% recovery) versus $(80.39 \%$ recovered in group $A)$, similar results were seen in the study the Similes et $a l^{10}$ On reviewing literature concerning the conservative treatment of acute appendicitis, I found that Tamsulosin had not been used before in the treatment of this condition, so this is the first time this drug is used in combination with antibiotics in the treatment of non-complicated acute appendicitis. Group B showed good response in relation to the time Table, 12 patients showed such signs in the first 10 hours versus 6 patients in group $A$.

Two patients in group $B$ showed no response to the conservative treatment and 10 patients from group A showed the same results, so appendicectomy was carried out.

Regaining of appetite and feeling of well being is good in both groups. However, group B did better than group A (84.6\% versus $73.07 \%)$ Table 2.

This study showed that elevated serum creactive protein level $(4 \mathrm{bmg} / \mathrm{dl})$ plays a key role in predicting failure of the conservative treatment in the first 24 hours, which is also seen in the study the Liu et $\mathrm{al}^{11}$ No calcified appendenicolith by US examination was detected in our patients so it has no role in the predication of failure of the conservative treatment contrary to the findings reported by others study. ${ }^{11}$

Recurrence of acute appendicitis 4 months after the first presentation was reported in $5.9 \%$ in group A compared to $9.8 \%$ in group B. High level of serum $\mathrm{C}$-reactive protein at presentation has 
predictive value of recurrence of acute appendicitis, comparable to other studies. ${ }^{11,12}$

Conservative treatment of acute appendicitis is safe because delaying of appendicectomy for 24 hours after presentation did not increase the rate of perforation or other complications as seen by others. $^{13-16}$

Tamsulosin which is an alpha 1A-receptor blocker and smooth muscle relaxant can result in better drainage and relieveing the intra luminal pressure in the inflamed appendix. It has minimal side effect, (mild dizziness). Adding it to the antibiotics combination in the conservative treatment of non-complicated appendicitis will definitely lead to a better results than antibiotics alone.

\section{REFERENCE}

1. Liu CD, McFaden DW. Acute abdomen and appendix. In: Greenfield LJ, (ed) Surgery principles and practice, Philadelphia Lippincott-Raven, 1997. 1246-1261.

2. Tehrani H Y. petros JG, Kumar PR, et al Marker of sever eappendicitis. Asm surg. 1999; 65:453-455.

3. Ricci MA, Trevisani MF, Beck WC. Acute appendicitis: A five year review. Am surg. 1991; 57: 301-305.

4. Larner AJ. The aetiology of appendicitis $\mathrm{Br} J$ hosp Med 1988; 39:540-2.

5. Andersson RE, Petzold MG. Nonsurgical treatment of appendiceal abscess or phlegmon: a systematic review and meta-analysis. Ann Surg; 2007; 264:741-8.

6. Mason RJ. Surgery for appendicitis: is it necessary? Surg Infect (Larchmt) 2008; 9: 481-488.
7. Bijen C, Van den Broek W, Bijen A, Ruiter P, Gouma D. Implication of removing a normal appendix. Digestive Surgery 2003; 20(3): 215-221.

8. Gill BD, Jenkins JR. Cost effective evaluation and treatment of acute abdomen. SurgClin North Am, 1996; 76: 71-82.

9. Hansson J, Korner U, Khorram-Manesh A, Solberg A, Lundholm K. Randomized clinical trial of antibiotic therapy versus appendicectomy as primary treatment of acute appendicitis in unselected patients. $\mathrm{Br} \mathrm{J}$ Surg; 2009; 96: 437-81.

10. Simillis C, Symeonides $P$, Shorthouse AJ, et al A meta-analysis comparing conservative treatment versus acute appendectomy for complicated appendicitis (abscess or phlegmon). Surgery; 2010; 147:818-829.

11. Liu K, Ahanchy S, Pisaneschi M, Lin I, Walter R. Can acute appendicitis be treated by antibiotics alone? Am Surg; 2007; 73: 1161-1165.

12. Tsai $H$, Shan $Y$, Lin $P$, Lin $X$, Chen C. Clinical analysis of the predicative factors for recurrent appendicitis after initial nonoperative treatment of perforated appendicitis. Am J Surg; 2006; 192: 311-6.

13. Shindoh J, Niwa $H$, Kawai $K$, ishiharai $Y$, Takabayashi N. Predictive factors for negative outcome in initial nonoperative management of suspected appendicitis. J GastroinestSurg; 2010; 14(2):309-14.

14. Abou-Nukta F, Bakhos C, Arroyo K, Koo Y, Martin J, Reinhold R. Effects of delaying appendicectomy for acute appendicitis for 12 to 24 hours. Arch Surg; 2006; 141: 504-7.

15. Colson M, Skinner KA, Punnington G. High negative appendicectomy rates are no longer acceptable. Am J surgint 2001 ; 174(6): 723-726.

16. Bachoo P, Mahomed A, Ninan R, Youngson G. Acute appendicitis: The continuing role for active observation. PediatrSurgInt 2001; 17(2-3): 125-128. 